\title{
The Fluctuating Nature of Risk Management Models
}

\author{
Dr. Diana Viljoen \\ North-West University (Vaal Triangle Campus) \\ E-mail:Diana.Viljoen@nwu.ac.za
}

Dr S. Wedzerai Musvoto

University of Auckland

\section{Doi:10.5901/mjss.2013.v4n13p211}

\section{Abstract}

This study discusses the credibility of using a fragmented approach to constructing risk management models. Current risk management models are based on the fragmentation approach which views inputs into the deterministic models as a single set of basic constituents, flowing through a model as a unit that spreads predictably throughout the whole process of predicting a particular perceived risk facing an entity. In most cases deterministic models are constructed based on the concept of measurement that is based on the measurement of structures having a natural concatenation that is representable by a sum and a weighted average. That is, current risk management models quantify social scientific phenomena through extensive measurement. However, studies in measurement indicate that extensive measurement has limited applications in social sciences due to the inadequate interpretation of the concatenation operation. This means that risk management models should be an insight into risk not an absolute truth to the notion that a specific risk is constituted of basic building blocks all working together towards its particular measurable absolute quantity. This study highlights that social scientific phenomena are not identifiable in terms of absolute truths but have properties that are in flux. For this reason, risk could be conditioned by other properties that the risk management model has not taken into account when measuring it. Hence, this study proposes a risk management perspective in terms of the universal flux of economic events and processes that move away from fixed measures of risk and towards a risk concept formulated in terms of multi-valued logics.

Keywords: risk management, fragmentation, deterministic theories, impoverishment theory, enrichment theory

\section{Introduction}

The purpose of this paper is to create an evolution process that moves away from fixed measures of risk towards a concept of risk formulated in terms of multi-valued logics. Model of risk formulated in terms of multi-valued logics are needed to address the fluctuating nature of social scientific phenomena. Current approaches to understanding the concept of risk are relative to social contexts. For example, Akhter (2010) and Iqtisad Al-islamy, (2003) view the Islamic community as experiencing risk exposure that is different from other cultural groups. This perspective reflects that risk is not independent of particular places and factual occurrences. Moreover, authors such as Flouris (2010), Prabakaran and RavicHandran (2010) and Jacobs (2010) argue that risk is relative to industry. Evidently, the existence of social contexts implies that human understanding of risk has been mediated by distorting appearances. According to Bauman (1992) the task of social scientific discipline is to facilitate the uncovering of true and objective understanding that has been distorted by appearances of social contexts. If this is the case, it may be argued that true understanding can only be achieved with the disappearance of social scientific discipline altogether. That is, social scientific disciplines must work themselves out of this commitment.

The argument presented above highlight that social sciences are only in existence because of a lack of transparency in social life. Hence, addressing the concept of risk in terms of mono-valued logics rigidly fixes the views about it when it is possible that the variability of the observed values of risk could be conditioned by other properties that permeate the social context that the model has not taken into account when quantifying it. In this case, it may be argued that the question of addressing risk must facilitate the emergence of the transparency of social life which will render the risk management discipline as a social science redundant. That is, the discipline of risk management must provide a way of managing risk that is not distorted by social boundaries and other agents of fragmented perceptions. Thus, if as noted above the current approaches to risk management advocate the existence of fragmentation in the discipline, then it may 
be argued that they are antisocial scientific in nature and absolute measure oriented.

Therefore, in order to facilitate the goal of risk management as a social science, it is necessary to find a way of addressing risk that advocates the existence of multi-valued logics of risk without any limits or barriers. This study commences with the literature review in section 2 . This is followed by a discussion of the current fragmented approach to risk management in section 3 . Section 4 and its subsections discuss various perspectives to a universal approach to risk management. In section 5 a contemplation of a universal model of risk management is made. Section 6 closes the study.

\section{Literature Review}

The nature of risk management models currently in use reveals that the notion of measure plays a key role in determining the general self world view and the way of life implicit in risk management. That is, to keep everything in its right measure is regarded as one of the essentials of risk management. Economic tragedies are considered a consequence of a business entity's failure to stay within the right measure. For, example, Flouris (2010) develops a model and identifies factors that can be used to evaluate aircraft performance. In this regard, the factors and the model of performance measurement is looked at as being some sort of comparison of an attribute with an external standard unit. Flouris' (2010) study has a particular interest in the causal factors of Take-Off Performance, Fuel Efficiency, and Speed. In this case for the former, the power factor was the most significant, while for the latter two the aerodynamics factor was more important. This means that the measures of power and aerodynamics factor have to stay within a certain range of an external standard for take off and optimum speed to occur respectively. Evidently, this conformance to standards can be seen as some sort of an outward display of an inner measure of optimum performance by an aircraft. From this perspective, it can be inducted that if one of the causal factors is beyond its proper measure, this means that the whole aircraft system is in disharmony such that it would loose its integrity and break up into pieces. This reflects that the ratios of causal factors should not be seen merely as numerical proportions, but it is some sort of a qualitative universal relationship. This implies that the various parts of the aircraft business are related in the idea of performance measurement. Thus, the essential reason for finding the causal factors is to satisfy the totality of inner proportions in its structure. Thus, it is a form of insight into the essence of everything about the perception that having the causal factors within a certain proportion of standards will bring harmony to the aircraft business.

Fixed views of risk can also be brought about by ways of life. For instance, Akhter (2010) views risk management as being of vital importance in Islam. He argues that risk is considered as existing only if it is definable in accordance with Islamic Shariah principles. It is clear from this that under Islamic law life is perceived as having problems only if the perceived problems are definable under Shariah. However, although problems in life may be successfully predicted under Shariah, it is also possible that sometimes the variability in the predictions could be conditioned by other properties that Shariah has not taken into account when measuring it. Akhter (2010) states it as follows: "Many Muslims misunderstand the concept of fate. For some Muslims believe that the future is in the hand of Allah, where they are facing with fatalistic mentality by putting themselves in the doctrine, whether one is rich or poor, happy or sad, it is fated by Allah. It is a good dealing with luck. In fact, efforts and prayers should precede this kind of belief"

This viewpoint highlights that viewing risk relative to a specific context gives a limited view of it. Leaving everything in the hands of the higher power enables an individual to overcome the state of incomprehension that requires an individual for an effort to make the uncertain certain. That is, one never reaches the state of incomprehension and as a result never experiences an effort to understand the incomprehensible. In this case, risk is never managed rather, undesirable events with unsavory consequences not definable within the confines of Shariah occur with impunity and possibly with the regularity of night and day. According to authors such as Akhter (2010) and Iqtisad Al-islamy (2003) Takaful is an Islamic way to share the financial risk of loss due to accidents and misfortunes that conforms to the norms and ethics of Shariah. This means that Takaful is only limited to viewing risk in terms of Sharia concepts. Thus, given that there are always interconnections between Shariah and other different ways of life, then, it may be argued that Takaful cannot account for risk factors not defined in Sharia.

Some authors have also approached risk management from the interdisciplinary perspective. For example, Prabakaran and RavicHandran (2010) took an Econophysics approach to risk management. This approach applies statistical physics methods to economical, financial and social problems. That is, it concerns the use of concepts from statistical physics in the description of financial systems. However, this study also took a deterministic approach to risk management by deriving the Black Scholes model of option pricing through a partial differential equation based on the construction of the complete hedge portfolio. This approach to option pricing is valid only in the case of European contingent claim with a simple payoff function. It does not cover other areas, for instance, path dependent derivatives. 
The concept of differential equations is used on functions whose arguments are known with certainty. But, when dealing with social scientific phenomena, arguments of functions should be viewed in terms of the universal flux of events. For instance, Musvoto (2010) argues that value; the basic building block in the measurement of return is a property in flux. He further stresses that because of its flux nature it must be measured using multi-valued logics. Hence, no single mathematical equation can quantify social scientific phenomena. Consequently, the Econo-physics approach gives, not a universal, but a limited approach to risk. Furthermore, it is important to note that mathematics studies nothing but hypotheses. If this is the case, it follows that mathematics acts as an empty vessel that can be filled with a wide range of goods. Peirce (1958:341) states it as follows: "Mathematics studies nothing by hypotheses, and is the only science which never enquires what the actual facts are".

If this is the case, it follows that using mathematics to represent something does not make the representation true. No formulation of hypotheses is necessary in the mathematical domain. Hypothesis formulation is necessary when studying domains other than mathematics. It follows that in other domains mathematics serves as a communication medium. Hence what it purports to represent must be unique and empirically testable. That is to say, the properties of the underlying phenomenon must be invariant. Similarly, Russell (1901) also states: "Mathematics, we are told, is the subject in which we never know what we are talking about or whether what we are saying is true"

This indicates that mathematics is an abstract structure that facilitates convenience in describing physical attributes. If this is the case, one may describe mathematics as a tool. A tool is as good as its user and the job it is used for. The appropriateness of mathematics in a particular case is a matter of judgment. Hence, the concept of appropriateness in this case is vague and ambiguous concept. That is, it is not bound by the law of the excluded middle. According to Chambers (1965) it is reasonable enough to make use of differential and the integral calculus when dealing naturally occurring phenomena. This is because cause and effect have criteria in natural science than in social science. That is, the criterion of reality; an account by which a reality is said by an observer to be real is universal in natural sciences than in social sciences. For this reason deterministic models in natural sciences are less likely to cause fragmentation as compared to social sciences. Therefore, caution should be exercised when applying mathematics to social scientific phenomena.

\section{Measurement and the concept of risk management}

In section 2 it has been noted that at the methodological level, research in risk management focuses on finding ways of quantifying risk. These insights are based on deterministic or causal theories. According to Heelan (1965) causal or deterministic theories are represented by the construction of an ideal relational norm for sensible data from which individual cases do not systematically diverge. In this way insights are only recognized if they accord with the ideal relational norm. In using these models patience is lost with any divergences. This stabilizes the modes of thought and protects them from change. Consider, for example, the following equation for the security market line; $E(r j)=r f+[E(r$ $m)-r f] B j$ (Haugens, 2001:215). The expected rate of return is defined as the subject of three independent variables. That is, it is the subject of the risk free rate, the risk premium and the beta of an asset. This means that the laws of risk management define by implicit definition how these are related through the concept of return with each other. They are defined operationally using measurement processes that map them onto the real line. It is such that given the initial values of the risk premium, the risk free rate and the beta, then, the expected rate of return at any future date can be calculated exactly.

However, before a deterministic model is constructed there are certain principles that the variables involved have to adhere to. For example, using the equation of the security market line it is clear that the concept of expected rate of return on a security is a composite entity that is composed of several elements. It is clear that the risk free rate, the risk premium and the beta of an asset affect the attribute "expected rate of return" of an asset. Thus, the expected rate of return of an asset is not a phenomenon that has a separate existence from the risk free rate, the risk premium and the beta of an asset. Rather, it exists as a result of the risk free rate, the risk premium and the beta of an asset. That is, there is no apparent empirical relational structure of the expected rate of return of an asset. The empirical relational structures that are apparent in the expected rate of return of an asset are those of the risk free rate, the risk premium and the beta of an asset. According to Luce et al (1971) a composite entity that has no apparent empirical relational structure and which exists only as a result of its components is measurable if its components are independently realizable. This means that the risk free rate, the risk premium and the beta of an asset must be capable of being measured independently of each other. But, authors such as Stamp (1981), Orbach (1978), Chambers (1997) and Musvoto (2010), note that value the basis on which the concept of return is constructed is as far as is known not measurable. This viewpoint highlights 
that if value is not measurable then the concept of return is also not measurable. If this is the case, it follows that fixed insights that form the overall world view in social sciences eventually come to be inadequate. Evidently, the case of the expected rate of return of an asset has indicated that mathematics can be used represent misconceptions. Whitehead (1938) also supports this view by stating that: "Mathematics is thought moving in the sphere of complete abstraction from any particular instance of what it is talking about. The certainty of mathematics depends on its complete abstract generality".

It is clear from this that the use of mathematics in constructing deterministic systems is only as good as the abstracted ideas. If mathematics is applied to a misconception, then the deterministic model is also a misconception. Furthermore, Heelan (1965) points out that a deterministic system is not a real system, for all its variables- even position are supposed to be defined with an infinite degree of precision, while data on any real system are obtainable only up to a certain degree of accuracy. For instance, in the equation of the security line all the variables involved in the models are defined with an infinite degree of precision. Moreover, studies in finance, especially tests on the security market line (Roll, 1977, 1978; Shanken, 1987; Fama and French, 1992 and Khotari et al, 1995) conducted tests on the capital asset pricing model, but did not succeed in establishing its empirical validity. This suggests that the application of mathematical laws to social sciences phenomena could be based on human ignorance of the concrete empirical properties of the individual cases. It is important to note that risk management models, like all systems that involve human or personal approach they are not free from error and subjective judgments. Similarly, Denenberg et al (1974) highlights that, exposures to risk are traceable to human actions. If this is the case, it may be argued that risk management is part of the process by which society is created. According to Hines (1988) every word, gesture and deed on the part of an individual or group is either, in conformity with social mores and thus, contributes to the maintenance of society as it is, or is deviant and will be tolerated only in small degree, unless the individual or group can change society-the latter is the story of the minority. In relation to the concept of risk it may be argued from this that risk management models reflect the mature of part of the society. Given that studies in finance have not established the empirical validity of the capital asset pricing model it may be argued that the current methodological approach to risk is based on arbitrarily isolating certain viewpoints in a setting and treating then as different. This creates confusion in the discourse centered on the question of sameness and difference. Hence, it then becomes difficult to understand why certain variable are included in the capital asset pricing model. Bohm (1988) argues that, in essence fragmentation is confusion around the question of difference and sameness. If this is the case it can be suggested that to be confused about what should be included what should not in the risk model is to be confused about everything. Hence, no one knows whether the model with work in a particular instance.

It is important to note that deterministic models such as the Black and Scholes (1973) model for European option pricing or the Econo-physics approach to European option pricing by Prabakaran and RavicHandran (2010) do not reflect insight into risk, but they become fixed testimony and an absolute true knowledge about risk. They quantify risk and represent it with a specific number. This perspective excludes insights of risk that are not distinguished by the model and falsely treats them as identical. Hence, current risk management models are used as a tool that distinguishes what is from what is not. According to Haugens (2001) the purpose of risk management models is to reduce the effects of financial losses. In most cases they measure the variability in the return of an investment over a period. In finance and accounting monetary units are used to represent the value of an investment (Musvoto, 2010). Thus, it follows that risk management models measure variations in value. Authors such as Ryan et al (2002), Staubus (2004) and Musvoto (2010) argue that value is a property in flux. If this is the case, it may be argued that it is inappropriate for a model to give a fixed insight into risk. Properties in flux are ever changing such that they consistently give fluid insights to investigators. Hence, deterministic or causal theories on risk must not be interpreted as giving a description of what is as it is, rather they should be seen an ever-changing form of insight that can point towards the idea of risk that is implicit but not completely describable. In this way no fixed forms of risk exist, the available forms also become an insight into the question about risk.

Moreover, in investment management the Black- Scholes (1973) option pricing formula is sometimes referred to as the Black- Scholes model (Haugens, 2001). This reference to it as a model raises the question of how or whether conceptually discontinuous finance models can express a continuous research tradition in the discipline. There is no successor or predecessor theory to this formula for pricing options. As a result there is no obvious convergence of theoretical concepts in finance that can be maintained. Moreover, finance is swarmed by examples of risk management models (e.g., Markowitz, 1952; Sharpe, 1964; Lintner, 1965; Mossin, 1966) that do not have successor or predecessor theories. The existence of successor or predecessor theories helps in the sense that each successor theory would interpret the predecessor theory in its own right as an approximation to it self. In this regard it may be argued that in 
some instances the risk management discipline has not fully appreciated the various usages of the term model. According to Heelan (1988: 244): "A model is a structure of ideal or empirical elements which is capable of entering into an appropriate semantical use to represent or elucidate a significant structure of something else, the modeled. "

The concept of representation employed in the definition of a model implies that the modeled is transformed onto the model by a specific function that guarantees that the model is a true representation of the modeled. It may therefore be argued that the modeled is transformed onto the model by an appropriately defined homomorphism. From the perspective of the concept of representation in measurement theory, the modeled must have qualitative empirical characteristics (Luce et al, 1971). This means that there must be an underlying theory that describes the transformation of the modeled onto the model. In hermeneutics literature a formal distinction between a theory and a model has been made. For example, according to Heelan, (1988:244):

\begin{abstract}
"A theory is (syntactically and ideally) an axiomatic system with undefined primitive terms; a model is any of its semantical interpretations; a semantical interpretation of a theory is any set of elements -abstract, as for example geometrical points or lines, or empirical, as for example, measured values of physical variables-which can be represented by a theory (onto which the theory can be mapped); a model then possesses a structure isomorphic with the theory. No theory in the above sense is exhaustively represented by one model, and any theory in this sense is underdetermined by any finite set of its models".
\end{abstract}

It is clear from this that each model must have an underlying theory and a model is a representation of a theory. It follows that, for example, with reference to the Black- Scholes (1973) model, there should be an underlying axiomatic system with undefined primitives that is isomorphic to the model. There should also be an explanation of how the axiomatic system comes to be applied in identifying the variables used in determining the price of an option. According Heelan, (1988) the process of modeling involves two stages. Firstly, the transformation from (axiomatic) theory to abstract model occurs, then from abstract model to observables. The equation that is used to determine the price of an option is a dimensionless abstract entity. It is imperceptible and thus unreal. Statements formulated in the equation are used to make particular assertions with realistic intent about the price of an option. The equation is developed from theoretical concepts about the value of an asset. In this case value is supposed to be empirical object in a particular world that is described by the equation. The link between value and the equation describes a unique relationship that is used to recognize the presence or absence of the (equation) model. As noted earlier value is a property in flux. This suggests that the relationship between value and the option pricing model is also in flux. As a result is not possible to tell whether the elements of the model are structurally related, and so in it may be argued that they are not the empirical elements of that which is modeled. Therefore, it may be argued that it is inappropriate to refer the method of pricing option as a model.

The discussion in the sections above also highlights that the epistemological position taken in risk management is grounded in the history of an alienated world. Current insights on risk reflect that it is considered to be relative to a specific historical context. Models for forecasting risk are developed from historical information (Valsamakis et al, 2005). Thus, the objectivity of risk models is relative to a historical context. If this is the case, it means that within the context of an individual act of risk cognition performed within a specific historical context the subject (observer) and the object (risk) are autonomous and on opposing sides. The only interaction between them is to produce information about risk. This act makes knowledge about risk relative to that particular single act of cognition within a specific historical context. Therefore, it can be concluded that the use of established finance models to get insights into risk varies with the variations in circumstances. Hence, no fixed insights into risk can be maintained.

\title{
4. The way forward in risk management
}

In the sections above, it has been noted that the concept of fragmentation in risk management originates in the fixing of insights that form the overall view on risk that follows on the habitual reliance on deterministic models or causal theories. It is important to note that the reality of the concept of risk goes beyond measures fixed by such forms of causal or deterministic theories.

In section 2 above, it has been noted that risk management can be used to reduce hardships in life caused by financial loss. In this sense the concept of risk management can also be considered to be a form of an extension to life. For this reason, it may be argued that since life is always evolving deterministic or causal insights of risk management would eventually cease to be adequate leading to confused and unclear risk management messages. However, when the discipline of risk management is open, without any fixed insights and other cultural barriers, it will cease to be a rigid 
discipline and fragmentation will disappear. The disappearance of fixed forms of risk would facilitate the emergence of a wholeness view of risk that gives rise to the disappearance of fixed measures of risk. When fixed forms of risk disappear, risk consciousness would no longer lie in the ideas that created deterministic models but rather has to come from the evolving wholeness risk perspective that also contains consciousness on deterministic models. In actual fact deterministic models would then be looked at as a subset of the evolving wholeness risk perspective. In this way, the wholeness and the fragmentation perspective of risk management cease to be opposing, but they become part of one universal view of looking at risk.

In section 2 it has also been pointed out that conceptual knowledge is produced by an act of abstraction. It has also been argued that in embracing wholeness it is necessary to abstract from all that is common and all that is not common to members of the set creating a norm that the individual cases can be compared. Thus, the concept of abstraction expresses a relation between terms which are themselves mutually and implicitly defined by the relations. Heelan (1965:13) states it as follows: "It seems to be, then, on the one hand, the highest common factor of a set, and for this reason it is said to abstract from all that is not common to members of the set; as, for example, from particular places and times: on the other hand, however, it is also the production or construction of an ideal norm with respect to which individuals can henceforth be compared as to the degree in which they conform to its rule or depart from it; as, for example, when a circle is defined as the locus of points equidistant from a fixed point called its centre".

Within this view it is clear that abstraction can occur in two ways. Firstly, the experimenter can start and investigation with full knowledge of all the members of the set. That is, in a particular world, an observer has full knowledge of its constituents. As a result a search is made by trial an error of a relationship amongst members of the set that satisfies a particular axiom that is of use and interest to the experimenter. In this regard it is said that an impoverished representation valid for a class of things is made (see, Heelan, 1965). With respect to the concept of risk management current investigators believe that a world view of elements of a particular set with a particular risk profile can be constructed. This would be based on the viewpoint that members of a set with a particular risk profile are known in their particularity. In this case the highest determinant of risk among the members of the set is determined. In finance, variation in return is regarded as the determinate of risk among the assets in a portfolio (see, Haugens, 2001). No other factors are sighted as indicators of risk. Changes in return is considered as if that is all there is to indicators of risk. Hence, this gives an impoverished representation of the risk profile of the members of the set as everything else is excluded. In order to reduce fragmentation from developing this view point should assume that the determinant of the risk profile of the set was known before the process of abstraction, but, just not as the highest determinant of the risk profile of the members of the set. In this case, risk management would become an act of abstraction. According to Heelan (1965) abstraction is a conscious act of comparing mental contents. In the light of this assertion it may be argued that there can never be an exhaustion of considerations of instances of possible highest determinants of the risk profile of the members of the set. That is, there will always be other instances of risk determinants that could induce the modification of the existing risk model if they are known. This approach to risk helps to make empirical generalizations about risk and at the same time it leaves room for improving the model. This prevents the fixation of one's thoughts towards a particular view of risk with limits and boundaries.

Fragmentation in risk management may be prevented by developing models that have contrary premises as the starting point. This is the second perspective of the concept of abstraction noted in the paragraph above known as the enrichment theory of abstraction (see, Heelan, 1965). According to this theory, knowledge of particular cases with which one starts with does not contain the concept, but that this is the end product of a complicated set of steps in which the analysis of sensible data is of key importance (Heelan, 1965:14). It is clear from this that a supposition or a proposition should not be assumed to be true in the absence of evidence to prove that this is the case. That is, it is assumed to be unsuitable unless proved otherwise. In this case risk management in Islam, the air line industry, the accounting practice or any other industry should be perceived to be different from other industries only after a series of tests have been conducted to shown this to be the case. Further more, a particular model of managing risk is prescribed to a particular case only after a series of steps and tests to show its suitability. For example, in the case of prescribing Takaful to Sharia (Akhter, 2010) as a form of managing risk in Islam, Takaful should have been treated as a formulated hypothesis that should have been subjected to testing and acceptance or rejection. This process would have established the value of Takaful in Islam financial planning as the ideal norm from which Sharia principles do not systematically diverge. However, there is no foundation in fact to support its prescription to Islam. Moreover, in formulating asset pricing models such as the Black and Scholes (1973) model or the Econo-physics approach to European option pricing by Prabakaran and RavicHandran (2010), the methodologies adopted do not posit the exclusion of other data as irrelevant as a consequence of the hypotheses they project. Rather they suppress or exclude particular cases from consideration to 
isolate variables for deterministic models and they do not retain them as part of a relational structure. In this case, the models fragment the approach to asset pricing and they cease to be part of a total view to risk. That is to say, for example, Prabakaran and RavicHandran (2010), in taking an Econo-physics approach to option pricing; reason should have been given, for example, for not using the principles of disciplines such as say theology or quantum mechanics to approach option pricing. By giving such a reason one makes them part of the whole option pricing model. This would enable the positive enrichment of the knowledge among disciplines and other particulars through the formulations of relations among them. Further more, this also facilitates the formulation of deterministic models of risk that are consistent with a pre-philosophic scientific concept. That is, consistence with the state of scientific knowing that forms the interface between raw data and the formulation of a mathematical equation or function. Consequently, risk management models would exhibit formal objectivity. In this case they should be an ideal norm that is constituted by an affirmation, which releases them from dependence on a knowing subject. Thus, they become objective in the strict or formal sense. As a result the models would be independent of particular places and factual occurrences. In this regard, this does not mean that risk management models become a one size fit all, rather, conformity to the model (standard) would mean correspondence to the formal consistence of the essence of risk while departures from it would mean its openness to multiple states. In this sense correspondence and non-correspondence would form a total or wholeness view of looking at risk.

\section{Conclusions and recommendations}

Although, risk management is currently considered to be a social scientific discipline that facilitates the uncovering of true and objective understanding that has been distorted by appearances of social contexts, it has paradoxically perpetuated the existence of distortions of true and objective understanding of the concept risk. In particular, it has been noted that deterministic models that are currently in use fix the general forms of thought about risk and thus contributes to fragmentation. Thus, they cease to be an insight into risk but rather an absolute truth to the notion that a specific risk is constituted of basic building blocks that work mechanically towards a particular measurable absolute quantity. Further more, it has been pointed out that the language used in risk in vague and ambiguous and does not adequately bring out the meaning of questions asked of risk. This view point perpetuates the fragmented view of risk and works against the very essence of a social scientific discipline.

In the light of the findings above, it has been recommended that fragmentation in the discipline may be reduced by adopting a wholeness view of risk. Specifically, adopting the following perspectives on risk has been recommended:

- Adopting the impoverishment and the enrichment theories of abstraction. These two theories enable flexibility with regard to insights about risk.

- Adopting the perspective of risk as an expansion of a form of life. In this way the concept of risk management would be used to reduce the state of incomprehension and thereby increasing certainty in life. In this way, the concept of risk management would be viewed in the context of all states of incomprehension irrespective of cultural barriers.

- It is also recommended that asking the right questions about risk prevents fragmentation. That is, each question contains presuppositions about risk which are largely implicit. If they are wrong or confused, then, the question about risk itself is wrong, and trying to model the management of risk around the answer to such a question has no meaning.

\section{References}

Akhter, W. (2010). Risk Management in Takaful, Enterprise Risk Management, Vol. 1, No. 1:E8

Bauman, Z. (1992). "Hermeneutics and Social Science, Approaches to Understanding", Gregg Revivals, USA

Black, F., Jensen, M.C., \& Scholes, M. (1972). "The Capital Asset Pricing Model: Some Empirical Tests, in M.C. Jensen. Studies in Theory of Capital Markets, ed. New York: Praeger

Black, F. \& Scholes, M. (1973). "The Pricing of Options and Corporate Liabilities", Journal of Political Economy (May-June)

Bohm, D. (1988). "Wholeness and the Implicate Order", Routledge, 11 New Fetter Lane, London EC4P 4EE

Chambers, R.J. (1997). "Wanted: Foundations of Accounting Measurement", Abacus, 34(1): 36-47.

Fama, E.F., \& French, K. R. (1992) "The Cross- Section of Expected Stock Returns, Journal of Finance (June).

Fama, E.F., \& Macbeth, J. (1974). "Tests of Multiperiod Two Parameter Model", Journal of Political Economy (May).

Flouris, F., (2010). Rationalizing Aircraft Performance Dynamic Modelling in Airline Fleet Planning Decisions, Enterprise Risk Management, Vol. 1, No. 1: E3. 
Haugen, R.A (2001). "Morden Investment Theory $5^{\text {th }}$ edition", Prentice Hall International, Inc.

Heelan, P.A. (1965). Quantum Mechanics and objectivity, The Hague: N Nijioff.

Heelan, P.A. (1988). Space-perception and the philosophy of science, University of California press, Berkeley and Los Angeles, California.

Hines, D. (1988) Financial Accounting: In Communicating Reality, We Construct Reality, Accounting Organizations and Society, Vol. 13, No.3, pp. 251-261.

Iqtisad Al-Islamu (Islamic Economics). (2003), "Risk Management in Islam-Takaful" as retrieved from www.islamicworld.net/economics/takaful.htm on Thursday, 26th October, 2006.

Jacobs, F. (2010) A Multidisciplinary Approach To Risk Management For Accounting Firms, The Journal of Applied Business Research, Vol. 18. No 4.

Khotari, S., Shanken, J., \& Sloan, R. (1995) "Another Look at the Cross-Section of Stock Returns, "Journal of Finance (March), pp.185220.

Lintner, J. (1965) "The Valuation of Risky Assets and the Selection of Risky Investments in Stock Portfolios and Capital Budgets," Review of Economics and Statistics, February.

Luce, R. D., Krantz, D.H.; Suppes, P. \& Tversk, A. (1971) "Foundations of Measurement, (Vol. 1) Additive and Polynomial representations", New York: Academic Press.

Markowitz, H.M. (1952). "Portfolio Selection ", Journal of Finance, December.

Mossin, J. (1966). "Equilibrium in a Capital Market, "Econometrica, October.

Musvoto, S.W. (2010). "The concept of a Scale in Accounting Measurement, South African Journal of Economic and Management Sciences, Vol. 13 (No 4).

Orbach, K.N. (1978). Accounting as a Mathematical Measurement Theoretic Discipline, Unpublished PhD Thesis, Texas A\& M University.

Prabakaran, S., Ravichandran, K. (2010) Black Scholes Model- An Econophysics Approach, Enterprise Risk Management, Vol. 1, No. 1:E7.

Peirce, C.S. (1958). Logic of Mathematics in relation to Education, in Values in a Universe of Chance, Philip P. Wiener (ed), Garden City, N.Y., Doubleday \& Company Inc, 1958, p341.

Roll, R. (1977). "A Critique of the Asset Pricing Theory's Tests: Part 1: On the Past and Potential Testability of the Theory, "Journal of Financial Economics (March).

Roll, R. (1978). "Ambiguity When Performance is measured by the Security Market Line, "Journal of Finance (September).

Russell, B., (1901). Mathematics and the Metaphysicians', in Robert W. Marks (ed), The growth of Mathematics, New York, Bantam Books, 1964, p26

Ryan, B., Scapens, R.W. \& Theobald, M. (2002). "Research Method and Methodology in finance and Accounting", Second Edition, Mitcham, Surrey, International, Padstow, Cornwall.

Shanken. J. (1987). "Multivariate Proxies and Asset Pricing Relations" Journal of Financial Economics, Vol.18.

Sharpe, W. F. (1964). "Capital Asset Prices: A Theory of Market Equilibrium, "Journal of Finance, September.

Stamp, E. (1981). "Why can Accounting not become a Science like Physics?", Abacus, June, 13-27

Staubus, G. J. (2004). "Two views of Accounting Measurement", Abacus, 40 (3): 265-279.

Whitehead, A.N. (1938). Science and the Modern World, Penguin Books, p34. 